\section{A ATUALIDADE DE NIETZSCHE PARA OS ESTUDOS SOBRE O CORPO: ANÁLISE DE LE NOUVEAU CULTE DU CORPS DE YANNIS CONSTANTINIDÈS}

NIETZSCHE'S CURRENT RELEVANCE FOR STUDIES ON THE BODY: ANALYSIS OF LE NOUVEAU CULTE DU CORPS, BY YANNIS CONSTANTINIDES

LA RELEVANCIA DE NIETZSCHE PARA LOS ESTUDIOS SOBRE EL CUERPO: ANÁLISIS DE LE NOUVEAU CULTE DU CORPS DE YANNIS CONSTANTINIDES

Carlos Herold Junior*
Palavras chave: Resenhas de livros. Corpo. Epistemologia. Filosofia.

Keywords: Book reviews. Body. Epistemology. Philosophy.

Palabras clave: Reseña de libros. Cuerpo. Epistemología. Filosofía.
Resumo: Nesta resenha é apresentada e analisada a obra Le nouveau culte du corps, escrita por Yannis Constantidinès. Sublinha-se que, embora a obra apresente alguns limites quando aborda o corpo na atualidade, ela se configura em um importante estímulo a novas pesquisas por focalizar o pensamento de Nietzsche, o que não tem sido muito usual no campo da Educação Física brasileira.
Abstract: This review presents and analyzes Yannis Constantidinès's work Le Nouveau Culte $d u$ Corps. Although the work has some limits when addressing today's body, it is important for encouraging new studies by focusing on Nietzsche's thinking, which has not been very usual in the field of Brazilian Physical Education.

Resumen: En esta reseña se presenta y analiza la obra Le nouveau culte du corps, escrita por Yannis Constantidinès. Cabe señalar que aunque el trabajo presenta algunas limitaciones cuando aborda el cuerpo en los días actuales, representa un importante estímulo para nuevas investigaciones, dado que enfoca el pensamiento de Nietzsche, lo que no ha sido muy habitual en el campo de la Educación Física brasileña.
*Universidade Estadual de Maringá Maringá, PR, Brasil.

E-mail: carlosherold@hotmail.com

Recebido em: 11-07-2015 Aprovado em: 24-08-2015

(c) (1) (8) Licence 
Yannis Constantinidès é doutor em filosofia e um estudioso da obra Nietzsche. Depois de outros livros (CONSTANTINIDÈS, 2001; 2009), em 2013 ele publicou Le nouveau culte du corps : dans les pas de Nietzsche ${ }^{1}$, com o selo editorial da François Bourin Éditeur. A obra é composta por cinco capítulos, em que são demonstradas variadas facetas socioculturais do cuidado que a atualidade devota ao corpo, todas elas escrutinadas tendo por base a filosofia nietzschiana.

O autor problematiza se a atenção à dimensão corpórea que lemos na obra de Nietzsche (BLONDEL, 2006) estaria, finalmente, realizada no "culto" em questão: "La réhabilitation du corps à laquelle s'était livré Nietzsche à rebours de I'histoire bimillénaire du christianisme semble donc avoir porté ses fruits"2" (p.9). A afirmação é irônica, pois o livro demonstra que esses pretendidos frutos fazem as advertências de Nietzsche ainda mais urgentes nos dias de hoje. Defendendo que Nietzsche assumia o "corps pour fil conducteur et non comme fil d'Ariane commode permettant de sortir du labyrinthe de la vie"33 (p.176), Constantinidès vê na "préoccupation permanente"4 (p.8) na busca do "corps idolâtré"5 (p.12) a retomada de um idealismo e de um moralismo cujas raízes foram estudadas e combatidas pelo filósofo alemão. Nos termos de Constantidinès, o diagnóstico é o seguinte:

Les mises en scène complaisantes du corps évacuent souvent la dimension charnelle pour n'en garder que l'apparence lisse et creuse, de sorte que l'on peut se demander si le vielle idéalisme moral ne perdure pas dans cette mise à distance symbolique de son propre corps, qui n'est valorisé que dans la mesure ou Il est délesté de son poids et de sés défauts supposés (CONSTANTIDINĖS, 2013, p.11). ${ }^{6}$

Com efeito, a sucessão dos capítulos se constrói para apresentar e avaliar as manifestações desse culto ao corpo por intermédio de uma crítica que "segue os passos" do autor de Assim falou Zaratustra (2011). O capítulo 1 intitula-se "Corps parfait". É nele que lemos o núcleo do raciocínio do autor, que caracteriza a ocupação hodierna com o corpo como uma "espiritualização" que redunda em uma "dérealisation des corps réels" (p.17), do mesmo modo que fazia (ou faz) o cristão na sua luta por se "défaire de sa chair réele pour être sauvé"g ( $p .23)$. Interessante observar que na atualidade, diferentemente do contexto em que se construiu 0 cristianismo, essa espiritualização do corpo também se manifeste na sua "hyperérotisation"10 (p.32), em um mundo no qual a busca pelo prazer (na vasta maioria das vezes, reduzido à sua dimensão sexual) transformou-se em "slogan publicitaire"11 (p.31). Isso gerou "hédonistes fatigués"12 (p.34) que concebem o prazer como um objetivo (e uma obrigação) a se alcançar por meio de uma cada vez mais precisa e antecedente racionalização. Ela é necessária, sobretudo,

\footnotetext{
1 Tradução livre: "O novo culto ao corpo: nos passos de Nietzsche".

2 Tradução livre: "A reabilitação do corpo a qual se ocupou Nietzsche, a contrapelo da história bimilenar do cristianismo, parece ter gerado seus frutos".

3 Tradução livre: "corpo como fio condutor e não como um cômodo Fio de Ariadne que permitiria sair do labirinto da vida".

4 Tradução livre: "preocupação permanente".

5 Tradução livre: "O corpo idolatrado".

6 Tradução livre: "As prazerosas encenações que se faz com o corpo eliminam frequentemente a dimensão carnal, mantendo apenas uma aparência lisa e oca, de modo que a gente pode se perguntar se o velho idealismo moral não perdura nesse distanciamento simbólico de seu próprio corpo, que é apenas valorizado na medida em que ele é descarregado de seu peso e de seus supostos defeitos".

7 Tradução livre: "O corpo perfeito".

8 Tradução livre: "Desrealização do corpo real".

9 Tradução livre: "desfazer de sua carne real para ser salvo".

10 Tradução livre: "Hipererotização".

11 Tradução livre: "Slogan publicitário".

12 Tradução livre: "Hedonistas fatigados".
} 
para aqueles que não têm o poder econômico para comprá-lo quando querem, compra essa que encurtaria o sofrimento que ainda persiste enquanto o gozo não é alcançado. Contra isso, Constantidinès (2013) vê em Nietzsche a defesa de uma "renaturalisation de l'homme"13 (p.39). Nela, o corpo não seria submetido à "rationalité apollinienne"14, assumida como o único caminho ao "délire dionsiaque"15 (p.32) a ser obtido apenas pela frieza do cálculo ou pelo dinheiro ou pela conjunção dos dois. Contrariamente ao que acontece no contemporâneo, em que o prazer deve ser frenético e nunca postergado ou negado ou, sequer, alcançado com dificuldades, uma "certaine ascèse"16 ( $p .45$ ) é vista como possibilidade de contornar o mencionado cansaço dos hedonistas racionalistas e/ou o comodismo anestesiado dos consumidores, cada vez mais insaciáveis pela falta de plenitude no êxtase que tanto buscam e tanto conseguem. Não se trata, nessa ascese, de se assumir um santo espírito controlando uma carne ignara, rebelde e dona de um preço valioso nas vitrines onde ela é exposta, mas um corpo que seria condição de um "individu synthétique, souverain"17(p.45), um do alvos de Nietzsche, segundo Constantidinès.

"Le corps medicalisé"18 é o título do segundo capítulo. Nele Constantidinès pensa a potência da ciência médica como uma pretendida sinalizadora de que, finalmente, o corpo teria sido alçado a uma condição diferente daquela em que fora posto nos últimos dois milênios. Aqui, a "obsession de faire mieux que la nature"19 (p.57) redunda em um "ideal Duracell"20 (p.63). A medicina teria se tornado a taumaturga possibilitadora e potencializadora do "culto ao corpo", agora reificado e examinado cada vez mais detalhadamente. As minúcias obtidas nos exames são dadas à vista ansiosa dos fiéis de uma congregação atormentada, que busca um paraíso livre da necessidade de encarar a abjeção que atribuem à inexorável decadência de nossas forças, que avança com o passar dos anos em direção à morte. A mencionada congregação é, torna-se ou reduz à situação de "paciente", afoita, todavia, em sua avidez por diagnósticos obtidos com as tecnologias de imagem e com os laudos assinados por especialistas, incontornáveis para a superação dos limites do organismo que diminuiria o alcance do pensamento e a força da moral defensora da tradição de ressentimento ao corpo, típica da cultura ocidental. Pensamento e moral que só conheceriam as fronteiras e os problemas pela indesejável e teimosa presença da carne. Fazendo frente a isso, Constantidinès avalia que Nietzsche é importante, pois nele temos uma filosofia que contrariaria o desvelamento dos meandros corporais com 0 fito de realizar um ocultamento da "arte de sofrer" (p.65): "En diabolisant la souffrance, notre époque a magnifié l'anesthésie généralisée, le 'sommeil profond', sans rêves, dont II est question dans le Zarathoustra"21 (p.65). Por essa razão, a técnica "diminui o corpo" (p.72) justamente na busca incessante de seu melhoramento, a ser realizado, por exemplo, na manipulação genética que toca o corpo de um modo a ampliar os dualismos de longa data. Citando o apelo das cirurgias e dos tratamentos estéticos, Constantidinès lança a seguinte provocação: nesse cenário, poderíamos falar, ainda, de corpo-próprio?: "Les injections de Botox ou de collagène figent d'ailleurs le visage en masque hiératique ou mortuaire, faisant disparaître avec les rides

\footnotetext{
13 Tradução livre: "renaturalização do homem".

14 Tradução livre: "racionalidade apolínea".

15 Tradução livre: "delírio dionisíaco".

16 Tradução livre: "certa ascese".

17 Tradução livre: "Indivíduo sintético, soberano".

18 Tradução livre: "O corpo medicalizado".

19 Tradução livre: "...obsessão de fazer melhor que a natureza".

20 Tradução livre: "Ideal Duracell".

21 Tradução livre: "Ao satanizar o sofrimento, nossa época aumenta a anestesia generalizada, o 'sono profundo', sem sonhos, ao qual questiona Zaratustra".
} 
sa mobilité et son expressivité, c'est-à-dire les caracteristiques essentielles du corps réel, humain"22(p.80). O rosto sempre belo com uma aparência "livremente" escolhida, repelindo a velhice e a morte para longe no sonho de um tempo estacionado numa juventude insuperável; teríamos aqui manifestações que resultam de uma biopolítica que faz da vida um "pure objet de contemplation"23(p.81).

Todavia, o corpo não é cultivado apenas em sua exterioridade vista nos contornos lisos da pele, no brilho de um sorriso "corrigido" e no alcance de medidas corporais "ideais". A evocação a um "corpo-próprio" no capítulo 2 é explorada no terceiro, em que são discutidos os impactos que a circulação de imagens do corpo gera na produção de subjetividades. Sendo impossível negar as críticas ao puritanismo dos costumes, mais visíveis e audíveis desde a década de 1960, não se pode virar as costas à constatação de que essa desejada liberação gerou "nouvelles normes tyranniques"24(p.85). Intitulado de "Habemos corpus!", o capítulo 3 aprofunda a crítica nietzschiana aos "desprezadores do corpo", que se lê no Assim Falou Zaratustra. Ladeando a atenção que é dada ao corpo e que é observada nos outros capítulos, nesse momento vemos que justamente a ubiquidade corporal é um "fantasme de renaître dans um corps, purifié, débarrassé de ses scorie", traço "bien vivace aujourd'hui”25(p.94), sobretudo, pelas numerosas possibilidades de se escolher a superação de qualquer determinação natural. Lembra Constantidinès que "Nietzsche réprouve la 'désanimalisation'de I'humanité', qui l'a éloignée de ses instincts les plus profonds et lui appris à en avoir honte"26(p.104). Contra essa situação, as reflexões buscam em Nietzsche uma "ética encarnada", exemplificada no livro naquela praticada pelo artista marcial que abre mão dos limites que separam interioridade e exterioridade, em que a força do espírito e dos punhos são as mesmas e manifestam uma fusão gerada e compreendida na prática de seu treinamento, e que não é reconhecida como importante devido ao peso dos preconceitos advindos da filosofia, da religião e da moral. Superar esse não reconhecimento proporcionaria condições para se construir um zelo corporal que inviabilizaria as já mencionadas pressões contemporâneas (herdeiras de toda a tradição criticada por Nietzsche) que se realizam por "normas tirânicas" a fazer apenas "hedonistas fatigados" com belos corpos expostos.

O capítulo 4, intitulado "L'homme mécanique aux parties remplaçables"27, tem como alvo os modos como o imperativo técnico que assistimos na atualidade redunda em mais um ímpeto da "déréalisation du corps"(p.118). Lançando mão das sempre interessantes possibilidades oferecidas pelo cinema para se pensar projetos futuristas, Constantidinès enxerga na ideia cartesiana do homem-máquina uma figura de grande força e que coloca no horizonte das subjetividades os "fantasmes gnostiques de pureté et d'indépendance par rapport au corps, avec une aversion toute particulière pour le corps à corps, le rapport immédiat à autrui"28(p.136). A busca por essa independência é exemplificada por Constantidinès em sua análise dos super-heróis que povoam as revistas em quadrinhos e, sobretudo hoje, as telas

22 Tradução livre: "As injeções de botox ou de colágeno congelam o rosto como uma máscara hierática ou mortuária, fazendo desaparecer com as rugas sua mobilidade e expressividade, ou seja, as características essenciais do corpo real, humano".

23 Tradução livre: "Puro objeto de contemplação".

24 Tradução livre: "Novas normas tirânicas".

25 Tradução livre: "a fantasia de renascer em um corpo purificado, livre de sua escória, [traço] bem persistente nos dias de hoje"

26 Tradução livre: 'Nietzsche reprova a 'desanimalização da humanidade', que a afastou de seus instintos mais profundos e lhe ensinou a ter vergonha deles.

27 Tradução livre: "O homem mecânico de partes substituíveis".

28 Tradução livre: "fantasias gnósticas de pureza e de independência em relação ao corpo, com uma aversão toda particular ao corpo a corpo, à relação imediata ao outro". 
do cinema. Na sua reflexão, eles não encarnariam o "Übermensche" de Nietzsche, mas sim o ressentimento que podemos ver em Clark Kent, em quem os superpoderes (afinal, sempre medrosamente escondidos) não o capacitam à superação da sua desajeitada mediocridade cotidiana. O mesmo ocorre com um Batman, um Capitão América ou um Homem-Aranha, que se apoiam tanto em um corpo musculoso quanto na potência técnico-econômica para seus feitos, tornados, desse modo, "reflet caricatural mais fidèle des hommes d'aujourd'hui, constamment tentés par la démesure et se berçant de l'illusion de plier leurs superpouvoirs techniques à leur bon vouloir"29 (p.142). Nesse ponto, o olhar nietzschiano de Constantidinès caracteriza a ubiquidade do corpo super-herói como "infantilismo" (p.142) que "quer sempre mais", mas pode cada vez menos malgré lui-même, diminuição proporcional à força manifesta em seus heroísmos. Mais uma vez, o cansaço do hedonismo compulsório, que caracteriza nossa época e que já manifestava indícios captados pelo filósofo alemão, é sublinhado. Lançando-se mão de reflexões dos Fragmentos Póstumos (NIETZSCHE, 2013), é lembrada a importância de considerar que "La maitrise dans l'excès permet en ce sens l'intensification de la vie"30 (p.145).

Nesse prisma, seriam, então, o esporte e a rotina ascética do treinamento práticas realizadoras das expectativas de Nietzsche? A ponderação sobre essa questão encontra-se no capítulo 5, "Corps et records"31. Terminar o livro focalizando o corpo nos esportes é uma estratégia interessante, afinal "Le Sport est à première vue le seul aspect du culte contemporain du corps qui soit réellement à la hauter des attentes de Nietzsche"32 (p.149). Entretanto, com o esporte sendo o "esperanto du monde"33(p.150) ou, o "onzième commandament" ${ }^{44}$ (p.150), nele lemos as mazelas culturais de nossa época a instrumentalizar ainda mais a corporeidade. Para desenvolver essa crítica, Constantidinès evidencia a distância do culto voltado às celebridades desportivas nos dias de hoje em relação à admiração da antiguidade grega às performances atléticas como meio de celebração do humano que se constrói no ágon e no jogo entre o apolíneo e o dionisíaco. Nessa ótica crítica, a erotização do corpo atlético que se vê na espetacularização desportiva dos dias de hoje, em que pese a sua marcante presença a atrair olhares de milhões de espectadores, é avaliada como mutilada, pois ela é subsumida à normatização comercial que imprime preços e marcas que se dão à vista no corpo desportista, merchandising guindado à condição de único regente e, literalmente, sustentador do "espetáculo". A frequência do doping, da manipulação de resultados, a exposição e a atração que exerce a banalidade (e, alguns casos, a estupidez) da vida pessoal dos "ídolos", tudo isso sinaliza que "Le sportif connaît certes parfaitement son corps, mais de l'extérieur, comme s'il s'agissait d corps d 'un autre" 35 (p.171), o que coloca atletas e consumidores em geral do fenômeno desportivo como partícipes de algo antípoda ao horizonte corporal concebido por Nietzsche.

Desenhar os contornos desse horizonte é o desafio que se colocou Constantidinès (2013). A validade da postura reflexiva apoiada em Nietzsche é endossada em obras e artigos publicados no Brasil nos últimos anos. A coletânea de Lins e Gadelha (2002) e o livro de

\footnotetext{
29 Tradução livre: "reflexo caricatural, mas fiel dos homens de hoje, constantemente tentados pela desmesura e que acalentam a ilusão de manobrar seus superpoderes técnicos à vontade".

30 Tradução livre: "O controle no excesso permite, nesse sentido, a intensificação da vida.

31 Tradução livre: "Corpo e recordes".

32 Tradução livre: "À primeira vista o esporte é o único aspecto do culto contemporâneo ao corpo que está realmente à altura das expectativas de Nietzsche".

33 Tradução livre: "O esperanto do mundo".

34 Tradução livre: "O décimo primeiro mandamento".

35 Tradução livre: "O esportista com certeza conhece seu corpo perfeitamente, mas a partir do exterior, como se se tratasse do corpo de um outro".
} 
Cordeiro (2012) são dois exemplos representativos de um universo que tem visto em Nietzsche uma fonte de reflexões para análise e crítica ao mundo contemporâneo, principalmente nos seus aspectos filosóficos atinentes ao corpo. Vale observar que essa empreitada de cruzar fronteiras temporais entre o nosso tempo e o tempo de grandes pensadores da história da filosofia para mostrar permanências teóricas, sociológicas e filosóficas é plena em dificuldades, mas, também, em possibilidades. O risco vale a pena, pois a premência de nossas angústias coloca esse diálogo como uma necessidade, como nos lembram Lins e Gadelha (2002):

A avaliação da atualidade ou inatualidade de uma obra ou de um autor, talvez não resida tanto no que eles expressam em si mesmo, em sua interioridade, [...] se não no modo como nos conectamos a eles, obra e autor, em função de um problema ou de uma dificuldade que se nos apresenta no presente como algo da ordem do intolerável, e que demanda de nós um escape ativo, um ultrapassamento (LINS; GADELHA, 2002, p.7).

Considerando os perigos e as promessas desse desafio, de um lado, feita a leitura das variadas questões abordadas no livro sobre a problemática do corpo no mundo atual, é possível avaliar que os esforços de Constantidinès (2013) ficam aquém de obras produzidas ou já traduzidas no Brasil, como é o caso de Ortega (2008), Sibilia (2002) e Le Breton (2003), Costa (2004), Fraga (2006) e Couto e Goellner (2012). Os diagnósticos feitos por Constantidinès não dialogam com a produção acadêmica existente sobre cada um dos temas de cada um dos capítulos, abundantes se considerarmos apenas a disponibilidade bibliográfica existente na França sobre a questão. Esse traço explicita a não inserção do autor nos meandros de toda a problemática relativa ao corpo no mundo atual, dando a impressão de que ele apenas se apoia em suas credenciais como filósofo especialista em Nietzsche para preencher essa lacuna bibliográfica. Não que a lacuna seja comprometedora da totalidade das análises, mas ela existe e é perceptível ao leitor que, minimamente, dialoga com parte do grande conjunto de obras que pensam o corpo na atualidade e na história.

Por outro lado, a grande positividade do livro de Constantidinès (2013) reside no agenciamento que ele faz do filósofo alemão, apoiando-se nele para pensar variáveis de grande valor aos estudos do corpo, como é o caso da relação entre corpo e técnica, passando pela medicina e pelo esporte. Nesse ponto pesa a favor do autor a familiaridade que possui com o filósofo. Dito de outro modo, se o livro perde qualidade quando fala sobre o campo que quer escrutinar, ele ganha quando lê Nietzsche sublinhando sua importância a essas questões. É importante salientar que é mais difícil encontrar estudos que dialoguem com o livro em tela, exatamente no que tange aos problemas assinalados quando se apresenta o panorama cultural sobre o corpo no mundo hodierno. Afinal, a presença de Nietzsche no pensamento de autores que circulam no contexto brasileiro é mais circunscrita ao potencial que esse "cruzamento de fronteiras históricas" possui na afirmação da importância do corpo no seio das grandes questões epistemológicas. Essa escolha ocorre em detrimento da consideração de fenômenos sociológicos de grande visibilidade, tais os que foram abordados por Constantidinès (2013) e que, de fato, sustentam a existência de um "problema ou de uma dificuldade" que nos leva a "um escape ativo, um ultrapassamento" (LINS e GADELHA, 2002, p.7), representado aqui por Nietzsche e sua filosofia ${ }^{36}$. Desse modo, na tensão entre os limites

36 Uma pesquisa nos arquivos da Movimento (UFRGS) com a palavra-chave "Nietzsche" devolve dois artigos, sendo que apenas no trabalho de Alves e Carvalho (2010) o filósofo alemão é utilizado para o estudo de questões que tocam a atualidade de problemáticas atinentes ao corpo e às práticas corporais. Isso pode sinalizar que no campo da Educação Física o pensamento nietzschiano ainda tem um grande espaço para alimentar importantes debates. A busca feita nos arquivos da Movimento (UFRGS) foi realizada em 8 jul.2015. 
e as potencialidades da obra de Constantidinès (2013), residem, ao mesmo tempo, problemas e estímulos a serem aproveitados por pesquisadores interessados nos pontos de contato entre questões epistemológicas, políticas e culturais concernentes ao corpo, as suas práticas e a sua educação.

\section{REFERÊNCIAS}

ALVES, Flávio Soares ; CARVALHO, Yara Maria de. Práticas corporais e grande saúde: um encontro possível. Movimento, v. 16, n.4, p. 229-244, 2010.

BLONDEL, Éric. Nietzsche, le corps et la culture : la philosophie comme généalogie philologique. 2.ed. Paris: L'Harmattan, 2006.

CONSTANTINIDĖS, Yannis. Le nouveau culte du corps : dans le pas de Nietzsche. Paris: François Bourin Éditeur, 2013.

CONSTANTINIDÈS, Yannis. Nietzsche : le eveillé. Paris: Ollendorff \& Desseins, 2009.

CONSTANTINIDĖS, Yannis. Nietzsche : les textes essentiels. Paris: Hachette, 2001.

CORDEIRO, Robson Costa. Corpo como grande razão: análise do fenômeno do corpo no pensamento de Friedrich Nietzsche. São Paulo: Annablume, 2012.

COSTA, Jurandir Sebastião Freire. 0 vestigio e a aura: corpo e consumismo na moral do espetáculo. Rio de Janeiro: Garamond, 2004.

COUTO, Edvaldo; GOELLNER, Silvana Villodre (Orgs.). Triunfo do corpo: polêmicas contemporâneas. Petrópolis: Vozes, 2012.

FRAGA, Alex Branco. Exercício da informação: governo dos corpos no mercado da vida ativa. Campinas: Autores Associados, 2006.

LE BRETON, David. Adeus ao corpo: antropologia e sociedade. São Paulo: Papirus, 2003.

LINS, Daniel; GADELHA, Sylvio. Nietzsche e Deleuze: o que pode o corpo. Rio de Janeiro: Relume e Dumará, 2002.

NIETZSCHE, Friedrich. Fragmentos póstumos. São Paulo: Forense Universitária, 2013.

NIETZSCHE, Friedrich. Assim falou Zaratustra. São Paulo: Companhia das Letras, 2011.

ORTEGA, Francisco Javier Guerrero. 0 corpo incerto: corporeidade, tecnologias médicas e cultura contemporânea. Rio de Janeiro: Garamond, 2008.

SIBILIA, Paula. O Homem Pós-Orgânico: corpo, subjetividade e tecnologias digitais. 3. ed. Rio de Janeiro: Relume Dumará, 2002. 


\section{Apoio:}

CNPq e Fundação Araucária do Paraná. 